have observed in certain cases a cessation of fever, a diminution of expectoration, and lessened liability to relapses.

In the normal person there is probably little if any hyperemia of the dependent lung during sleep. In a tuberculous patient, however, a moderate degree of hyperemia is undoubtedly produced by prolonged rest on the affected side. We would seem to have confirmation of this probability in several patients who have found hemorthages to occur over a period of years whenever they have slept on the side of their diseased lung.

It would seem wise in future to observe all patients with nocturnal or early morning hemorrhages from the point of view of the side on which they have rested at night.

In certain patients with heart lesions the rarity of pulmonary tuberculosis has been thought to be due to a possible back pressure of the blood in the pulmonary circulation.

Fagge $^{3}$ found only four cases of pulmonary tuberculosis with mitral stenosis in thirty years' records of postmortems at Guy's Hospital.

In searching the literature in regard to the above mentioned simple procedure little can be found.

Mendelsohn ${ }^{4}$ advocated patients with pulmonary tuberculosis lying on the side of the healthy lung so that the discharge assisted by gravity could more easily flow to the bronchus and so be thrown off.

Link $^{5}$ in 1902 suggested tuberculous patients resting for a few hours during the day on the side of the tuberculous lung, but from his article it would seem did not thoroughly carry out the suggestion.

Link, however, calls attention to the possibility

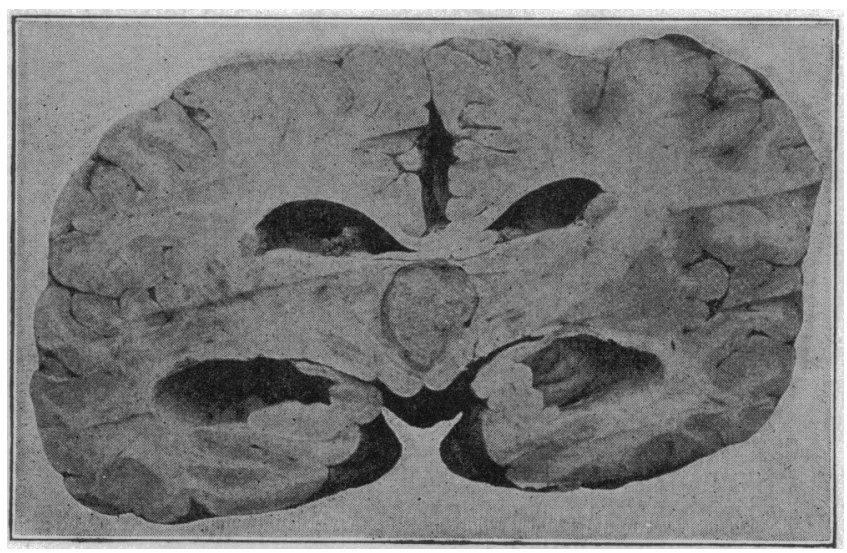

Fig. 1 (Case 1).-Tumor filling third ventricle.

\section{TUMORS OF THE THIRD AND FOURTH VENTRICLES *}

\author{
PETER BASSOE, M.D. \\ CHICAGO
}

I. TUMORS OF THE THIRD VENTRICLE

In 1910 T. H. Weisenburg, ${ }^{1}$ on the basis of thirty reported cases with necropsy, succeeded in bringing out the salient features of tumors arising within the third ventricle and thus establishing a syndrome which necessarily is ill defined, as the symptoms are either due to pressure on neighboring structures or to secondary hydrocephalus. Among the former symptoms are paralysis of the associated ocular movements, exophthalmos, large pupils with impaired reaction, and ataxia of the cerebellar type. Of the few cases reported later, one by Lewis J. Pollock ${ }^{2}$ may be mentioned, as the appearance of the tumor on cross section of the brain closely resembles that of the one to be related here.

CASE 1.-Boy, 14 years old, with rather precocious genital and hairy development suggesting hyperpinealism. Limitation of ocular movements. Papillitis and blindness. Ataxia. Headache; drowsiness; mental dulness. Soft glioma filling third ventricle; secondary hydrocephalus.

A boy 14 years old was admitted to the surgical service of Dr. Carl B. Davis in the Presbyterian Hospital, Aug. 24, 1915, having been referred to him by Dr. J. C. Bucher of Verona, Ill. The parents and two brothers and sisters are in good health. The patient had previously been healthy and had done well in school. He had been of a solitary and shut-in disposition and had used tobacco to excess for four or five years. Two months before admittance he had daily headache for a week or ten days, then it subsided, and he had of hyperemia and also of the added rest of the affected lung by adopting such a procedure. Link observed the diminished respiratory murmur of the dependent lung. ${ }^{6}$

3. Fagge, in Fishberg: Pulmonary Tuberculosis.

4. Mendelsohn: Ueber therapie Beeinflussung der Expektorationen durch Heilmittel der Hypurgie, Berl. Klin., 1899

5. Link: Lagerung der Kranken bein einseitiger Spitzentuberkulose, Ztschr. f. Tuberk., iii, 480 .

6. The following references may also be consulted:

Rubel: Funktionelle Ruhe der Lungen, etc., Ztschr. f. Tuberkulose,

Gerhardt: Die Lage der Kranken als Heilmittel, Ztschr. f. Kranken pflege, 1898, p. 88 .

Galliard: Les Pleuresies providentielles, Sem. méd. 1897, p. 214.

Von Leyden: Der Comfoit der Kranken als Heilfaktor, Ztschr. Krankenpflege, 1898, xx.

Reusner: Die Expectoration bei allein erhaltener Zwerchfellathmung, St. Petersb, med, Wchnschr., 1898, No. 2.

Charcoal in Local Treatment of Gonorrhea.-An abstract in the Correspondenz-Blatt says that Oppenheim and Schlifka of Vienna report excellent results from injection into the urethra, once a day, of a suspension of $5 \mathrm{gm}$. of animal charcoal in 0.5 liter (quart) of tepid water. Acute gonorrhea, suppurating profusely, with numerous gonococci, was permanently cured by this alone, but the cure could be hastened by combining it with an astringent $(1: 6,000$ potassium permanganate). The procedure proved most promptly effectual in acute posterior. urethritis with diffusely purulent turbid urine. They said thet this charcoal lavage does not irritate or harm in any way. not complained of it for a month before coming to the hospital. Two weeks before admittance he suddenly became blind, and a few days later he had an epileptiform attack. From the time of the onset of headache he gradually grew dull mentally.

Examination by the writer on the day of admission: Well developed boy with healthy, ruddy complexion. The head is rather large, the circumference being $58.5 \mathrm{~cm}$. He has a very distinct mustache for his age, also abundant pubic hair. $\mathrm{He}$ is dull, drowsy and apathetic and cannot give a reliable account of his previous history. The pupils are equal, wide and do not react to light or in accommodation. When at rest the eyeballs diverge a little. There is apparently no light perception. The movements of the eyeballs, especially the left one, are much limited. The left eye is only moved 15 degrees outward, the right one twice as much. Marked bilateral choked disk with hemorrhages. Corneal reflexes present. He lies on his back with head turned to the left and holds the neck stiff. Any movement of the head, especially to the right, is resisted and seems to cause headache. The gait is very unsteady and he has a tendency to fall finger to nose and heel to knee tests. Examination of sensation is unsatisfactory, but apparently there is some diminution

* Read before the Section on Nervous and Mental Diseases at the Sixty-Seventh Annual Session of the American Medical Association, Detroit, June, 1916

1. Weisenburg, T. H.: Brain, 1910, xxxiii, 236

2. Pollock, Lewis J Tumor of the Third Ventricle, The Journal backward. Ataxia of the extremities is demonstrated by the 
of pain sense on the left side of the face. The facial muscles appear somewhat weak on both sides, and the greatest weakness is found in the shutting of the left eye. The watch is heard in both ears. Knee jerks are absent; left ankle jerk absent, right present. Abdominal and cremasteric reflexes present. Wrist and elbow jerks present. No Babinski sign. The genitalia are very well developed.

Blood examination: Hemoglobin, 82 per cent.; red cells, $6,000,000$; white cells, 15,900 .

Urine: Normal except for excess of phosphates. The Wassermann test is negative with blood and spinal fluid, and

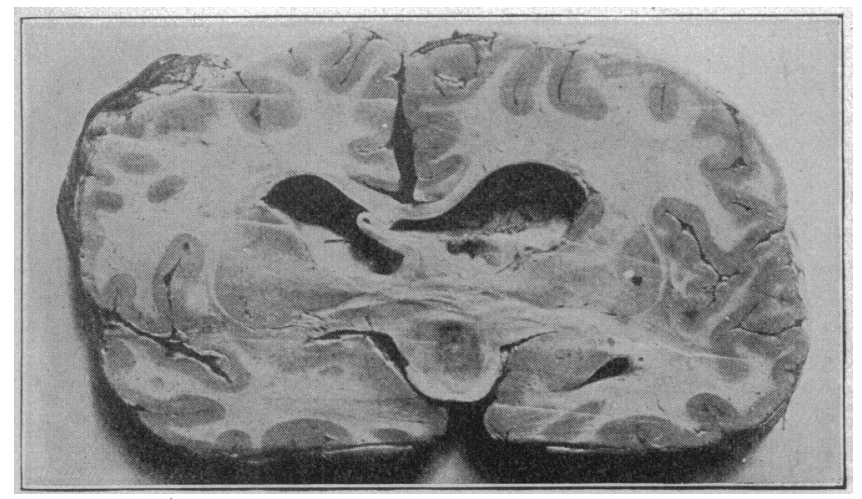

Fig. 2 (Case 1).-Anterior portion of tumor.

the latter shows no increase in cells or globulin and gives a negative Lange colloidal gold test.

August 27, ophthalmoscopic examination by Dr. C. G. Darling shows a swelling of 8 diopters in the right eye and 4 or 5 in the left eye.

August 30: Getting worse mentally; seems disoriented; soils bed; has vomited his breakfast a few times; little headache, always tendency to fall backward.

A diagnosis of brain tumor was made, most likely located in the region of the corpora quadrigemina or pineal body, although the possibility of a cerebellar site could not be excluded. However, only a decompression operation was advised.

August 31: Right subtemporal decompression was made by Dr. Davis. The brain was found to be under unusually high pressure. The temperature, which previously had not exceeded $99 \mathrm{~F}$., rose to 102.4 six hours after the operation, and reached 104.8 before death, which occurred thirty hours after the operation.

Necropsy.-The brain weighs $1,450 \mathrm{gm}$. The sulci are shallow and the gyri flattened. On the right side is a bulging area corresponding to the recent decompression operation. On the inferior surface there is a marked downward bulging in the region of the pineal body. The latter structure, however, is of normal appearance. After hardening in liquor formaldehydi the brain was cut by means of frontal sections. The bulging referred to is found to be caused by the great distention of the lateral ventricles. A soft, light gray tumor is found to fill the third ventricle (Fig. 1). Posteriorly it lies free in the ventricle, plugging the opening of the aqueduct, and appears to have a slight capsule. Its upper surface bulges into and completely closes the foramina of Monro (Fig. 2). In front of this level the tumor is seen to extend in a downward direction in front of the infundibulum, the anterior end being $9 \mathrm{~mm}$. in front of the anterior border of the optic chiasma. The bulging at the base produced by this forward growth of the tumor begins at about the center of the base of the infundibulum and extends $2.3 \mathrm{~cm}$. forward, or $1.1 \mathrm{~cm}$. in front of the chiasma. The greatest anteroposterior measurement of the tumor in the third ventricle is $4.7 \mathrm{~cm}$. Transversely it measures $1.9 \mathrm{~cm}$. and vertically $2.1 \mathrm{~cm}$. The degree of hydrocephalus may be judged from Figure 3, showing the anterior portion of the lateral ventricles.

Histologic Examination.-This tumor is very edematous, loose in texture, and in most places shows considerable evidence of tissue degeneration. Small hemorrhagic areas are seen. The cells are very variable in size and shape, and only in a few places is there any significant arrangement of them.

Many of the cells have the appearance of astrocytes, and very abundant fine fibers are seen in Van Giesen specimens. Their appearance suggests glia; but the Weigert glia stain failed, probably on account of the tissue degeneration. On the border of the tumor tissue remains of the ependymai layer of cells may be seen, in the form of palisade-like columns (Fig. 4).

\section{TUMORS OF THE FOURTH VENTRICLE}

Tumors of the fourth ventricle are much more common than those of the third ventricle. They also produce symptoms by inducing hydrocephalus and by exerting pressure on neighboring structures, in this case the cerebellum, pons and medulla. Like all other posterior fossa tumors, they may produce stiffness of the neck and occipital pain; and as increase in cells and globulin as well as in the pressure of the spinal fluid is common, a clinical resemblance to meningitis sometimes exists. This is well shown in our Case 2, while Case 3 presented the picture of cerebellar tumor, and in Cases 4 and 5 mental symptoms predominated. In another case reported by the writer ${ }^{3}$ in which, in addition to the fourth ventricle tumor, another ependymal glioma in the frontal lobes was present, mental symptoms entirely dominated the clinical picture. Sudden death is very frequent in these cases.

CASE 2.-Early symptoms suggestive of meningitis. Cloudy spinal fuid with increase in cells, both polymorphonuclear and mononuclear. Papillitis. Duration five and one-half months. Sudden death. Very large tumor in fourth ventricle, breaking through and almost surrounding pons.

A boy $2 \frac{1}{2}$ years old, formerly well, was seen with $\mathrm{Dr}$. H. F. Helmholz at the Evanston Hospital, Feb. 15, 1914. Ten weeks previously he had been taken ill with vomiting which occurred every day. There was slight fever, the temperature occasionally reaching $101 \mathrm{~F}$. The child seemed to suffer from headache. Strabismus and nystagmus had been noted, but there were no convulsions.

Blood examination, February 12: Hemoglobin, 75 per cent.; reds, 5,000,000; white cells, 15,000 .

Examination.-Slight bilateral papillitis; no Kernig sign, no rigidity; knee and ankle jerks weak; abdominal reflexes

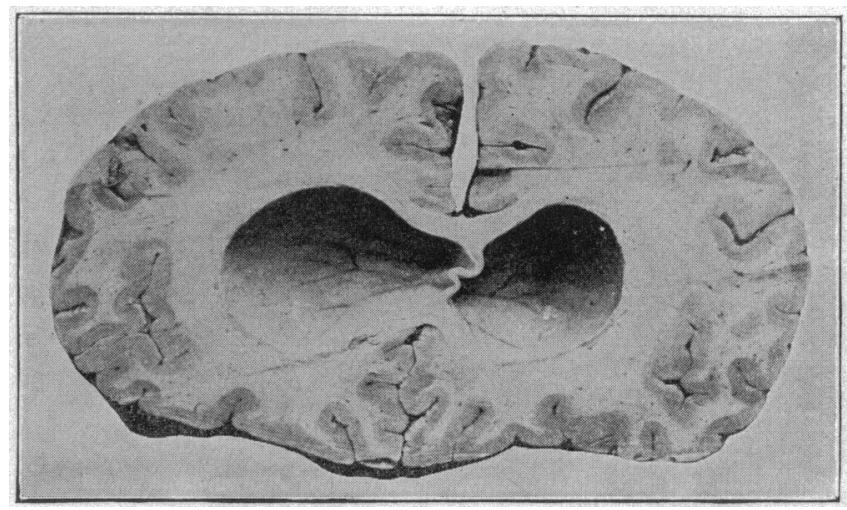

Fig. 3 (Case 1).-Anterior portion of distended lateral ventricles.

weak, left weaker than right; doubtful left Babinski sign. The child was fairly bright and good natured. On making lumbar puncture the fluid was cloudy and escaped in a stream. There were 363 cells per cubic millimeter, about two thirds of which were polymorphonuclear. No bacteria were found in smears or cultures. As tuberculosis was suspected, a guinea-pig was inoculated but did not develop the disease.

For further information regarding this case I am entirely indebted to Dr. Helmholz and to Drs. W. O. Hoffman and

3. Bassoe, Peter: Multiple Ependymal Glioma, Arch. Int. Med., September, 1908, p. 194 
A. B. Schwartz, in whose article on the permanganate reduction index of the cerebrospinal fluid $^{4}$ this case appears as Case 1. February 17, slight rigidity of the neck appeared with suggestion of the Kernig sign on the left side. There was a distinct Babinski sign on the left side; right plantar reflex normal. February 18, spinal fluid still opalescent but pressure not increased. The patient improved, and on February 24 he could stand up and walk when led by the hand. The headache was less severe, and vomiting had ceased. The spinal fluid was clear and showed a few lymphocytes, but no bacteria. A "weakly positive" Wassermann reaction was obtained with the spinal fluid, and the Lange gold test on this and three subsequent occasions gave a weakly positive reaction of syphilitic type, which may be represented as follows: 0122100000 (maximum reaction would be 5). Mercurial treatment was now commenced and the patient continued to improve. March 2, a weakly positive Wassermann test with the blood was obtained. March 17, he walked well and had gained in weight. Lange test negative in all dilutions. No puncture was then made for a month, and by April 16 the headache had returned and marked ataxia had developed so he could not sit up in bed with the eyes closed. There was some relief after lumbar puncture. The Lange test was negative.

May 9: In spite of repeated lumbar punctures, the symptoms became more severe.

May 25: Frequent vomiting. Unable to sit up without swaying from side to side. Mind clear. Wassermann test with spinal fluid negative.

June 9: Died quite suddenly without any special symptoms having developed.

Necropsy.-After hardening in liquor formaldehydi the brain weighs $1,385 \mathrm{gm}$. The gyri are large and flattened, the sulci shallow. The cerebellar lobes at the base are seen to be separated by a light gray tumor mass which extends forward and upward so as to nearly surround the pons, only a space $8 \mathrm{~mm}$. being left uncovered (Fig. 5). The width of the tumor

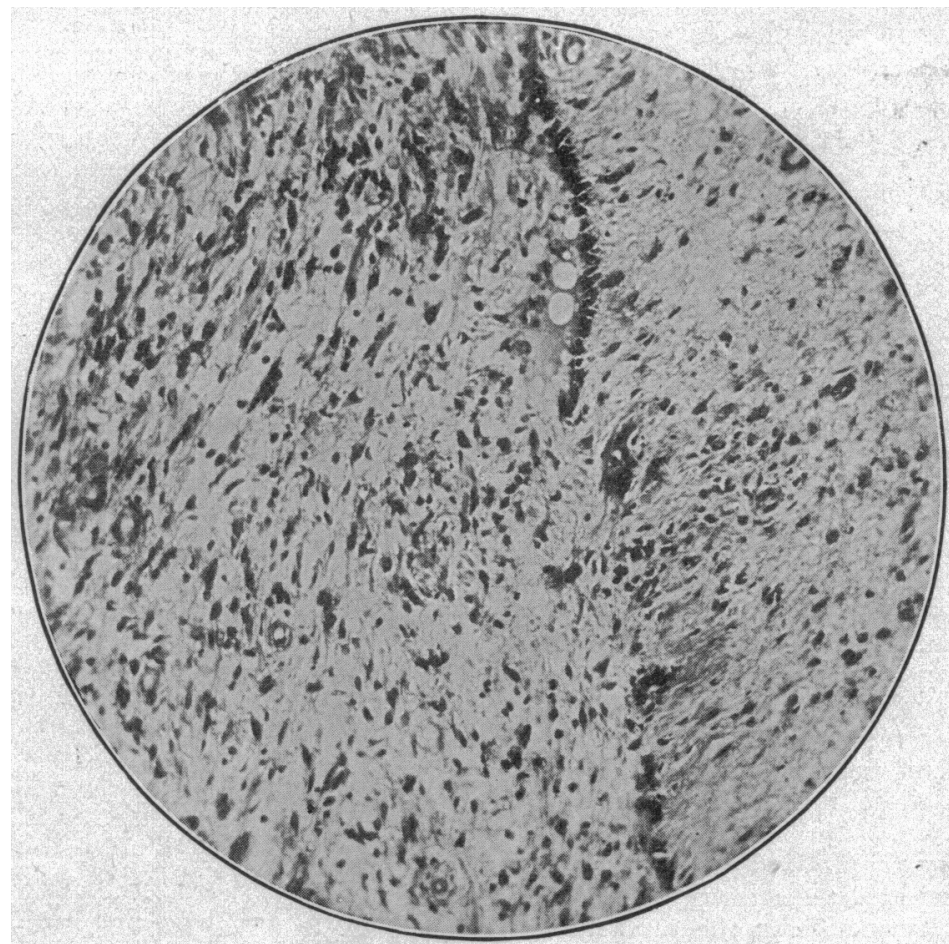

Fig. 4 (Case 1).-Photomicrograph of tumor showing remains of ependymal been perfectly well up to the age of 4 years, when she had measies. Two or three months later she began to stumble in walking and would usually turn the eyes to one side. She had headache for a month at that time. The legs gradually grew worse. In November, 1911, a neurologist discovered optic neuritis, made a probable diagnosis of cerebellar tumor and advised operation, but his advice was disregarded. After a fall, four days before my examination, she began to vomit and became semistuporous.

- Examination.-The head is unusually large, but this is probably not significant, as the six healthy brothers and sisters also have large heads. The patient is dull and drowsy, and does not at all cooperate in the examination. The pupils are equal, of medium width, and react normally. Bilateral papillitis of moderate degree, probably of long standing. No nystagmus; no facial paralysis. Ocular movements probably normal. All tendon reflexes increased. Both legs spastic, bilateral ankle clonus and Babinski sign. The upper abdominal reflexes were equal and normal, the lower doubtful. A diagnosis was made of tumor in the posterior fossa, probably cerebellar, and operation advised. October 15, a suboccipital operation was performed by Dr. Charles E. Kahlke, but the patient died before the dura was opened.

Through the courtesy of Dr. W. Henry Wilson, pathologist to Hahnemann Hospital, I later had an opportunity to examine the brain, which had been hardened in liquor formaldehydi and afterward weighed $820 \mathrm{gm}$. The upper part of the fourth ventricle is filled by a grayish, smooth, rounded tumor, attached to the floor for a distance of $2 \mathrm{~cm}$. (Fig. 8). Its width is $15 \mathrm{~mm}$., height $7 \mathrm{~mm}$. Its inferior border is 2 $\mathrm{cm}$. above the end of the ventricle. On $\mathrm{making}$ longitudinal section it appears as if the tumor at its upper end extends for at least $1 \mathrm{~cm}$. into the pons. The brain shows very marked hydrocephalus (Fig. 9).

Histologic Examination. - The tumor is a glioma, rich in cells.

Longitudinal sections of the pons beneath the tumor between the cerebellar lobes is $3 \mathrm{~cm}$., and it extends $4 \mathrm{~cm}$. backward from the posterior border of the bulb. Figure 6 shows how the tumor fills and enormously expands the fourth ventricle. Hemorrhagic areas are seen in its substance. The pons and bulb are greatly flattened. The aqueduct is much dilated, the ventricles only moderately so. The tumor deeply indents the cerebellum on both sides, more so on the right, but does not grow into this organ or into the pons or bulb.

Histologic Examination.-The tumor shows characteristic structure of glioma, with typical rosette or fan-shaped arrangement of the cells about the vessels. Fine glia fibers are demonstrable by the Weigert glia stain (Fig. 7 ).

CASE 3.-Clinical picture of cerebellar tumor. Death on operating table after exposure of dura over cerebellum. Small tumor in upper part of fourth ventricle. Marked hydrocephalus.

A girl $5 \frac{1}{2}$ years old was examined, Oct. 8, 1912, in consultation with Dr. W. R. Parkes of Evanston. The child had

4. Hoffman, W. O., and Schwartz, A. B.: The Permanganate Reduction Index of Cerebrospinal Fluid, Arch. Int. Med., February, 1916, tion Ind 293 . show that the latter extends well into the pons substance. The border is diffuse. Pal-Weigert specimens show no persistent nerve fibers in the portion of the tumor growing into the pons.

A section of the upper part of the cervical cord, stained by the Pal-Weigert method, shows the posterior columns and the direct cerebellar tracts to be well preserved and deeply stained in comparison to the rest of the cord. The pyramidal and Gowers' tracts are decidedly degenerated.

CASE 4.-Man of 58 years with symptoms of cardiovascular disease. Mental deterioration, delusions of persecution and delirious episode during last months of his life. Small sessile glioma in floor of fourth ventricle. External and internal hydrocephalus.

A cab driver 58 years old was admitted to the service of Dr. B. W. Sippy in the Presbyterian Hospital, Oct. 5, 1906. $\mathrm{He}$ had been a hard working and temperate man. $\mathrm{He}$ had syphilis at 48 . For several years he had occasionally had sudden momentary sensations that he was going to fall when walking, a sensation of constriction around the chest, and shortness of breath on exertion. There had been a general acute articular rheumatism at 17 and at 30 years of age, and 
feeling of weakness for at least three years but no loss in weight, and the appetite had been good. While in the hospital he was suspicious of other patients, even claiming that they had robbed him and tried to murder him. His memory for recent events became greatly impaired. He gradually grew irritable and excitable, and three weeks after admittance became delirious, had involuntary discharges, and had to be

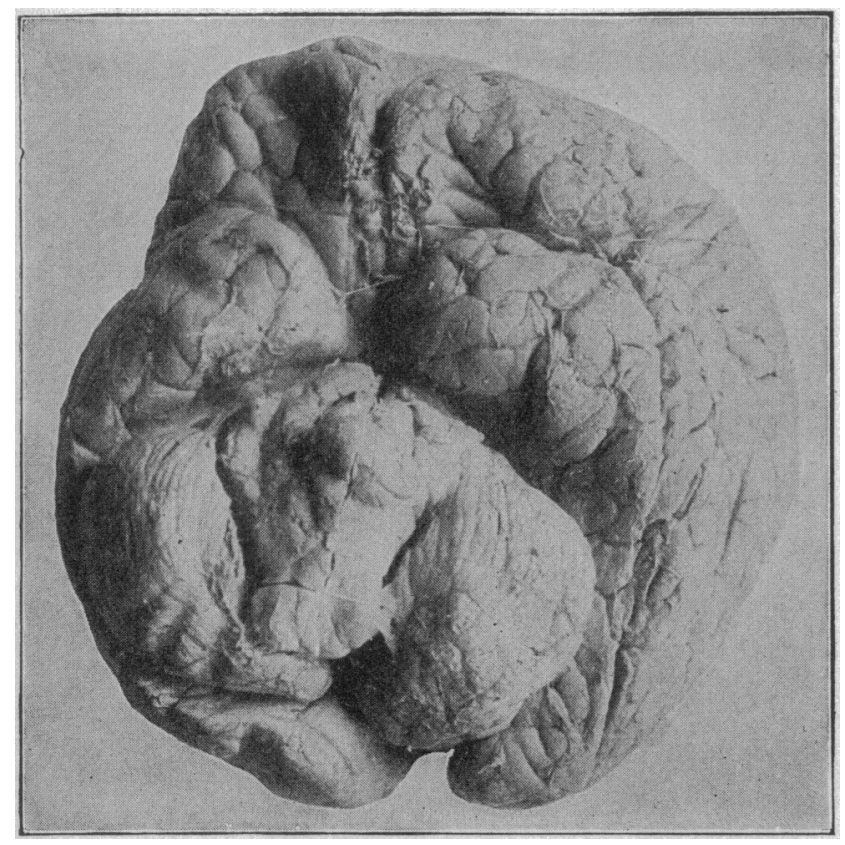

Fig. 5 (Case 2).-Base of brain showing tumor nearly encircling pons.

restrained. After three days the delirium subsided and he returned to his previous mental state. He also developed a pleuritic effusion in the hospital and at first there were both a systolic and a presystolic murmur at the apex with irregular rhythm, but later the presystolic murmur disappeared and the systolic one became very faint. The eye grounds were examined twice and found to be normal. The blood pressure at first was 190, later 104. The urine frequently contained albumin and hyaline and granular casts. The hospital record is silent as to any symptoms and findings on the part of the nervous system other than those mentioned. The patient died, Feb. 8, 1907.

Necropsy.-At the necropsy the following anatomic diagnosis was recorded: arteriosclerosis; thrombosis of left iliac artery; retrograde thrombus formation in the aorta; edema of lungs, fibrinous pericarditis; hypertrophy of heart; chronic mitral and aortic endocarditis; hypertrophy of prostate and bladder; multiple rectal ulcers; tumor of fourth ventricle; external and internal hydrocephalus; atrophy of brain.

On opening the fourth ventricle a growth was seen attached to its floor and extending into the lumen of the ventricle but not reaching its roof. It was $1.5 \mathrm{~cm}$. long, $1.7 \mathrm{~cm}$. wide, and $18 \mathrm{~cm}$. in height (Fig. 10). The protocol described the brain as "soft and tense to bursting." There was a large amount of subdural fluid, and the pia-arachnoid was very edematous. The ventricles were dilated.

Histologic Examination.-The tumor shows the structure of ependymal glioma, with some areas consisting mostly of fine fibers while in others cells predominate. In. the center of the tumor small areas of calcification, as well as hyaline concretions, are seen (Fig. 11).

CASE 5.-Man, aged 38 at death. For several years attacks of headache, dizziness and vomiting. Early relative weakness in left side. Mild mental deterioration and symptoms of cardiac and renal disease. Death from hypostatic pneumonia. Sessile tumor in floor of fourth ventricle. ${ }^{5}$

5. This patient was only under my observation for a period of a few months. For a large part of the clinical history I am indebted to few months. For a large part of the clinical history I am indebted to Drs. Achilles Davis and Milton Portis, and for the necr
A business man, married, 37 years old, was first seen by the writer, Nov. 15, 1912. There was some suspicion of syphilis in the father. No brothers or sisters. No previous illnesses of importance. Venereal disease denied.

Present Illness.-The onset was very gradual. About five years before death (1909) he began having brief attacks of nausea and vertigo, later associated with headache of increasing severity, lasting in the beginning a few hours only, later several days. From about June, 1911, more or less vertigo was experienced every day, worse in the mornings and after heavy meals, and especially when stooping. Vomiting occurred with severe attacks of headache. He began losing flesh in 1910, but when examined by Dr. Portis in November, 1911, he still weighed 195 pounds; one year later, 152 pounds. Dr. Portis found gastric hyperacidity and low blood pressure, (96 to 108). In 1911 he began complaining of clumsiness and lack of control of the movements of the left hand and arm, especially annoying when shaving or driving his automobile. A tendency to drag the left foot and to stagger to the left was also noted at this time. When first seen by Dr. Davis in March, 1912, physical examination was practically negative. The Wassermann test with the blood was made several times, generally negative, once or twice "doubtful." Later in 1912 the weakness in the left side increased and he showed a suspicious overconfidence in his business ability. In October of the same year he became involved in business failure and legal prosecution, and showed apparent rapid increase in mental deterioration which, however, possibly to some extent was simulated.

Examination by the writer, Nov. 15, 1912: Patient carries himself like an old man and talks slowly and feebly. Memory probably somewhat impaired. Decided relative weakness in left arm and leg, latter slightly atrophic. Both knee and ankle jerks brisk, left more so. Pulse 68 . No other findings.

Dec. 8, 1912, reexamined. Looks better; has had headache every day, worse when sitting up. Less difference in reflexes on right side and left side, but left leg appears weaker. Blood pressure 100, pulse 64. Wassermann test with blood and spinal fluid negative. The latter shows no increase in cells or globulin. Lange colloidal gold test negative. Ophthalmoscopic examination negative. Attacks of severe headache, with vomiting, recurred frequently. The patient was last

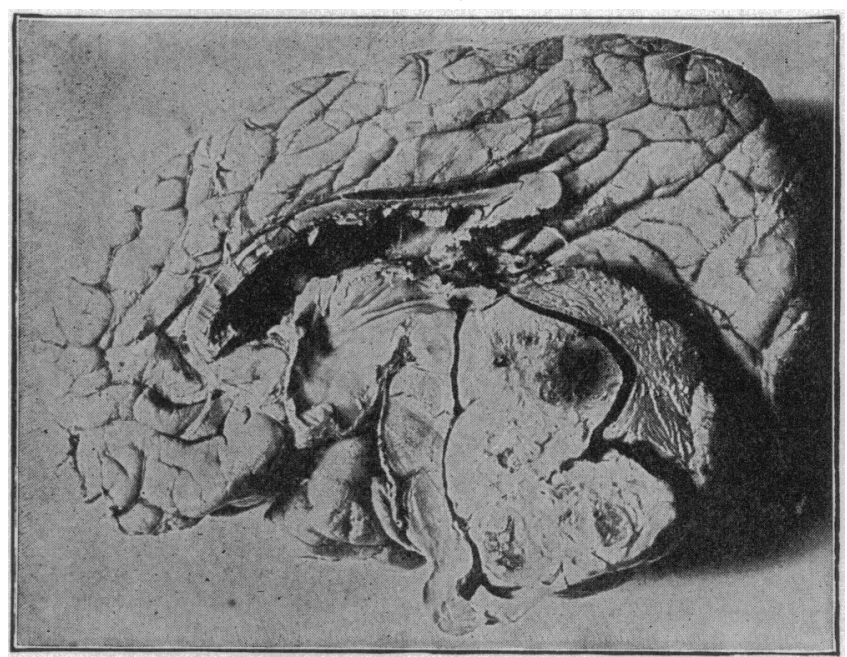

Fig. 6 (Case 2).-Median section of brain showing tumor fllling fourth ventricle.

seen by me in 1913. Dr. Davis kindly informed me that he was under his continued observation from the fall of 1913 until his death in April, 1914. The weakness and atrophy of the left limbs increased. The eye grounds remained normal, but headache, vomiting and dizziness remained prominent symptoms. Albumin and casts appeared in the urine. Repeated examinations of the spinal fluid showed nothing abnormal. No sensory disturbance developed. A few days before death he developed hypostatic pneumonia which determined the fatal issue. 
Necropsy.-This was held by Dr. F. Robert Zeit, who kindly placed his notes and the gross and microscopic specimens at my disposal. The following anatomic diagnosis was made by Dr. Zeit: Ependymal glioma of fourth ventricle. Internal hydrocephalus. Edema of brain. Chronic parenchymatous nephritis (large, red kidney). Hypertrophy of heart. Brown induration of lungs. Terminal hypostatic pneumonia. Healed tubercle in apex of left lung. Chronic granular gastritis and hemorrhagic acute duodenitis.

The specimen further examined by me consisted of the cerebellum, pons and medulla. The cerebellum had been opened from above so as to expose the fourth ventricle. This is greatly distended, and on the left side it forms a cavity occupying the greater part of the cerebellar hemisphere. To the left of the median line the ventricle is the seat of a sessile, grayish-red growth measuring $3.3 \mathrm{~cm}$. in length, $3.5 \mathrm{~cm}$. transversely, and projecting $8 \mathrm{~mm}$. into the ventricle (Fig. 12). The cavity extends $2 \mathrm{~cm}$. to the left of the tumor margin and has a smooth lining. The cerebellar substance covering the dilated ventricle on the left side is only 3 to $5 \mathrm{~mm}$. in thickness. The under surface of the cerebellum shows marked molding at the edge of the foramen magnum.

The other gross findings are summarized in the anatomic diagnosis. It was particularly noted that nothing suggestive

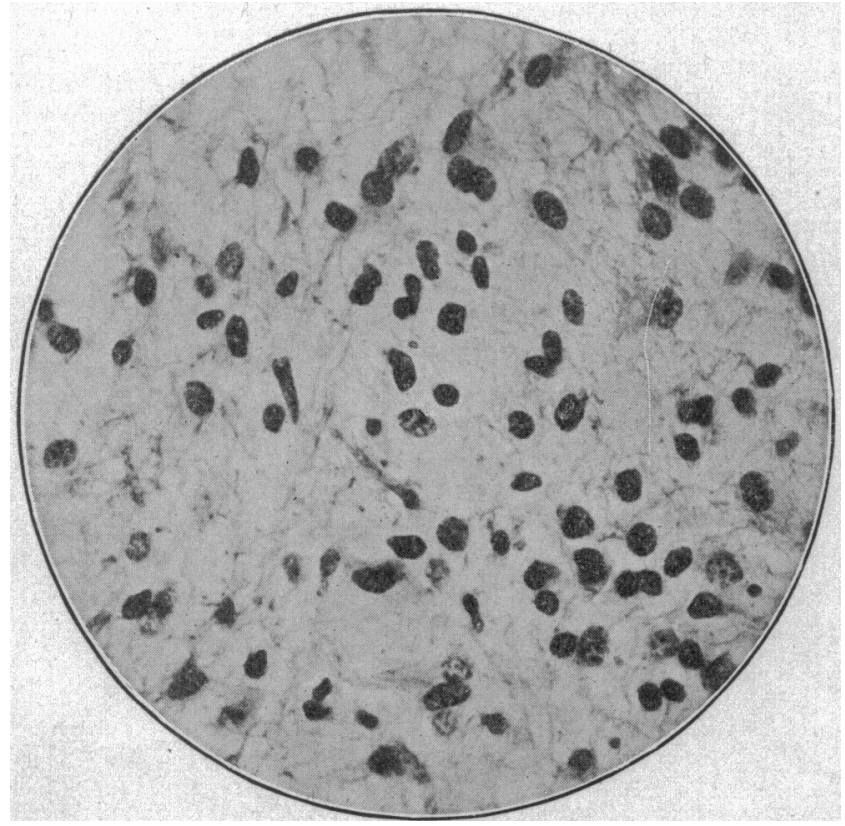

Fig. 7 (Case 2).-Photomicrograph showing glia fibers and cells.

of a syphilitic lesion was found in the body, that there was very little sclerosis of the aorta, and that the vessels at the base of the brain had soft and thin walls. The skull and dura showed no changes. The convolutions of the brain were flattened, and the lateral and third ventricles were considerably dilated. Each kidney weighed $230 \mathrm{gm}$., and the capsules were adherent. The heart weighed $330 \mathrm{gm}$.

Histologic Examination.-The structure is that of a somewhat degenerated ependymal glioma. Numerous hyaline concretions are seen (Fig. 13), mostly derived from obliterated vessels.

A Pal-Weigert specimen of the bulb shows considerable degeneration of the dorsal portion of the pyramids, adjoining the olives, while their ventral (superficial) portions are well preserved. Still more marked degeneration is found in the raphe and in the interolivary fibers. This portion of the bulb is seen in hematoxylin-eosin and Van Gieson preparations to be thickly set with pale blue, hyaline, round bodies.

CASE 6.-Boy 5 years old. Onset with headache, then adiposity, unsteadiness, papillitis and failing vision. Genitalia said to have become smaller. Later blindness, two convulsive seizures, marked general weakness. Decompressive operation, hyperpyrexia, death. Tumor filling fourth ventricle.
A boy 5 years old was referred by Dr. Wright C. Williams of Peoria, Feb. 16, 1914. The patient was the sixth of eight children, the others being well. In the summer of 1913 he began to suffer from headache; later he grew fat and the genitals grew smaller. In the beginning of December he was brought to Dr. Williams on account of headache and a tendency to stumble. There was a slight papillitis, especially in the right eye, and vision was considerably reduced. It failed rapidly, and he became completely blind about the first of January. Late in December there were two convulsive sei-

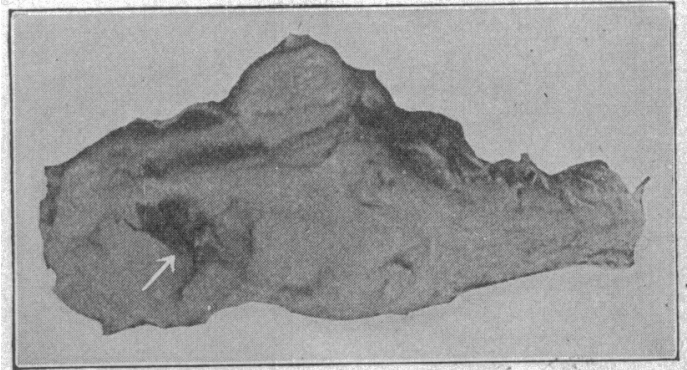

Fig. 8.(Case 3).-Tumor of fourth ventricle.

zures three days apart. The Wassermann test was negative with both blood and spinal fluid, and two examinations of the latter for cells were négative. Urine negative.

Examination.-Fat child with flabby musculature. Penis small; both testicles in the scrotum. Patient very weak; cannot walk or sit up unaided or hold the head erect for any length of time. Totally blind. Pupils equal and dilated. Constant rotary nystagmoid movements drawing the eyeballs. upward and to the left. The movement to the left is rapid, the return slow. The eyes wink with the beginning of each nystagmoid movement. Dr. E. V. L. Brown made the following note: "Right and left optic nerve atrophy, secondary to marked choked disks; nerve head swollen (right plus 2); scleral and pigment rings not seen; retinae not involved; vessels narrow; pupils react to light only with light directly in front." Hearing normal. Apparently slight paresis of right side of face and right arm. Knee jerks absent; ankle jerks slightly increased, right more so; bilateral Babinski sign. The patient could draw the knees up but could not raise the knees from the bed. Probably no sensory disturbance. Abdominal reflexes not obtained at first, but later

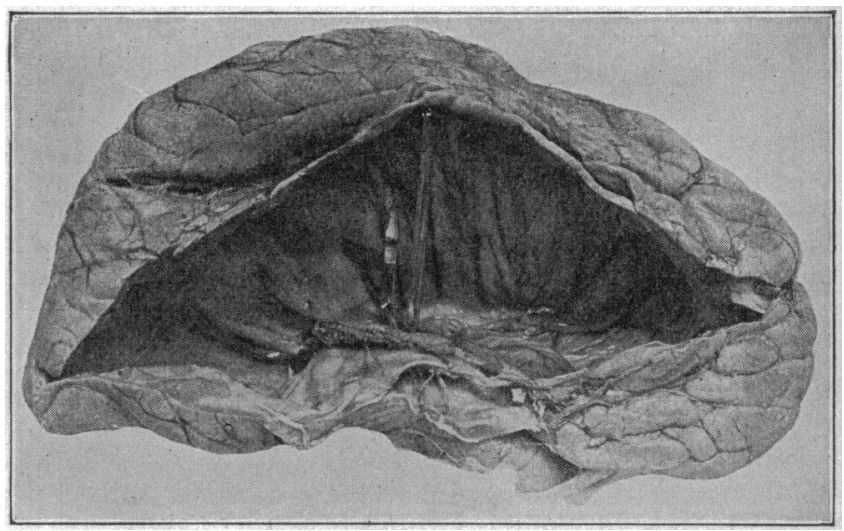

Fig. 9. (Case 3).-Median section of brain showing marked hydro cephalus.

weak response was obtained on both sides. Soft, blowing heart murmur at the base. Roentgen-ray examination showed normal sella turcica. Blood examination: reds, 4,940,000; whites, 11,000; hemoglobin, 98. Urine normal.

February 25: Right subtemporal decompression made by Dr. Dean Lewis. The brain pressure was very high. Soon afterward the arms and later the entire body twitched continually. The temperature rose to $108.6 \mathrm{~F}$. before death, eighteen hours after the operation. 
Necropsy.-The brain weighed $1,170 \mathrm{gm}$. Marked downward bulging of the third ventricle was noted. The hypophysis was normal. The fourth ventricle was filled by a soft tumor the greatest dimension of which was $5 \mathrm{~cm}$. transversely and $3.8 \mathrm{~cm}$. vertically. The tumor was connected with the pons. Unfortunately, I missed the opportunity to examine the hardened and sectioned brain, and failed to learn to what extent the pons was actually invaded. All of the ventricles were considerably distended. The tumor tissue examined microscopically was said to be made up of masses of darkly staining small round cells and to show considerable necrosis and in places small hemorrhages.

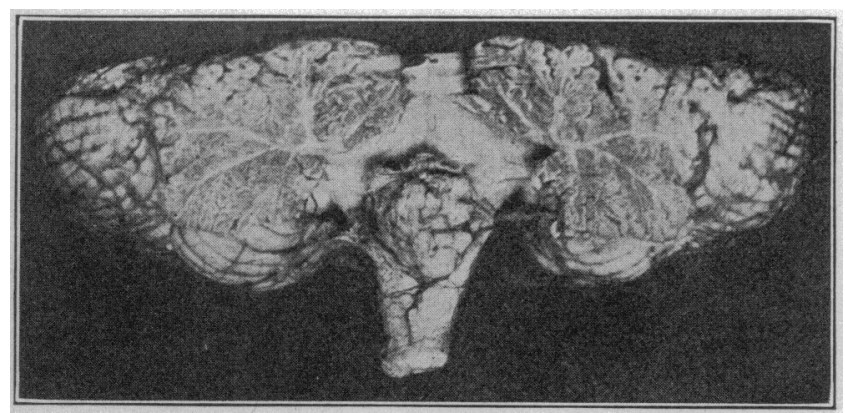

Fig. 10 (Case 4).-Tumor in fourth ventricle.

The histologic diagnosis was small round-cell sarcoma. (I have not had an opportunity to see the specimens, and know from experience that sarcoma and cellular glioma are frequently confused.)

\section{THERAPEUTIC REMARKS}

Of these six patients three were operated on, all with disastrous results. In Cases 1 and 6 subtemporal decompression was followed by death in thirty and eighteen hours, respectively. In Case 3 a suboccipital operation resulted in death on the table before the dura was opened. In Case 2 repeated lumbar puncture apparently gave temporary relief at times, but it naturally would more often be found to aggravate the symptoms. Any sudden interference with the intracranial pressure condition appears to be dangerous, and this applies to the three methods used in the present cases. The danger of death from the application of any of the usual cerebral decompressive methods, the practical impossibility of making a clinical diagnosis of intraventricular tumor, and the difficulty of access to these ventricles all conspire to place tumors of the third and fourth ventricles among inoperable brain tumors in the minds of most neurologists and surgeons. However, the writer must agree with Professor Anton ${ }^{6}$ of Halle that operative removal of tumors of the fourth ventricle is not theoretically impossible. Some of them arise from the choroid plexus and are not attached to the walls, and others are only attached above, to the cerebellar vermes. It would, therefore, seem possible in such cases to enter the ventricle through the vermes, or below, and possibly remove the tumor, provided the pressure in the posterior fossa was not too high at the time of operation. In order to obtain a favorable pressure condition, Anton recommends operating at a period of relative freedom from headache and other pressure symptoms, and to perform a preliminary callosal puncture or puncture of one of the lateral ventricles. The only practical sug-

6. Anton: Arch. f. Psychiat., 1911, xlviii, 523. gestion to offer is this one, that if symptoms strongly point to posterior fossa tumor and nothing is found in the cerebellar hemispheres, then the surgeon may go a step further and also explore the fourth ventricle, at the same sitting, if a preliminary callosal puncture has been made, or else after an interval of a few days.

30 North Michigan Avenue.

\section{ABSTRACT OF DISCUSSION}

Dr. Theodore H. Weisendurg, Philadelphia: Years ago I wrote a paper on this subject in which I reviewed the cases of tumor of the third ventricle reported in the literature. I wrote this paper because I had had three cases of tumor of the third ventricle in every one of which diagnosis of tumor of the cerebellum was made. On investigation I found that of the forty cases reported, not a single one had ever been diagnosed properly during life. I then tried to establish a symptom complex. Most cases of tumor of the third ventricle cause cerebellar asynergy; they all have internal hydrocephalus, with a paraparesis of all four limbs with the accompanying increase of reflexes. With this there is nearly always paresis of associated ocular movement upward. This symptom group would seem to be especially indicative of tumor of the third ventricle, and Dr. Bassoe's case would seem to confirm this. I believe that we can make a diagnosis of tumor of the third ventricle in life, for I have been able to do so. Tumors of the fourth ventricle are quite difficult to diagnose. Not in a single case, I believe, has a diagnosis been made in life. In most of these cases the diagnosis has been tumor of the cerebellum. Dr. Mills and I tried to show that there is such a thing as $x^{2}$ 
cerebellum, and found and removed the tumor. Localization in the cerebellum should be advanced, that is, we should not be content to make diagnosis of tumor of the cerebellum; but should be able to say that a lesion is located in a certain and definite part of the cerebellum.

Dr. Tom A. Williams, Washington, D. C.: In tumors of the third ventricle there is another sign to be found which was not brought out by Dr. Bassoe in his case report, and I do not remember whether it was brought out by Dr. Wei-

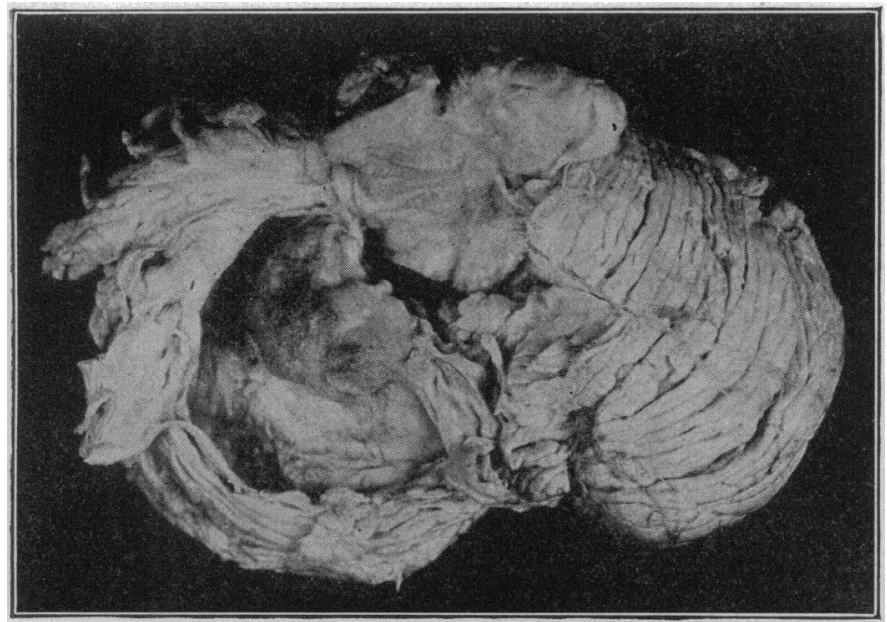

Fig. 12 (Case 5).-Tumor on left side of fourth ventricle.

senburg in his original communication. The sign is one that "was shown in a case we had in Washington in 1907 which was diagnosed during life and in which we had a postmortem. There were photographs in the case. Diagnosis was made of tumor in the third ventricle or of the corpora quadrigemina, involving both sides, and it was made by reason of several findings: First, because of compiete ophthalmoplegia; second, from the eye grounds because of the marked choking of the disk in conjunction with the extreme rapidity of the onset; and, third, on account of the decerebrate attitude of the patient. This attitude is one that was, I believe, first described in connection with physiologic experiments, and consists of the quadrupedal progression reaction, namely: Suppose you scratch the right arm of the subject, there will immediately be, let us say, flexion of the right arm, and at the same time there will occur flexion of the counter leg, along with extension of the contralateral arm and extension of the homolateral leg; that is to say, the attitude and movement of quadrupedal progression. This is due to impulses from the spinal centers when separated from cerebral control. On that ground mainly the diagnosis in this case was made. And photographs show the child's position after stimulation of one area in various attitudes, as described, in that position, which is the position of the dog's progression. Hughlings Jackson published a case showing this attitude. I do not remember whether that was a case of this particular lesion, neither do I know whether a necropsy was obtained. The sign may depend on rapidity of onset, because it is possible that, in the gradual progress of a unilateral tumor slowly invading the third ventricle, gradual adaptation may prevent this particular syndrome or the patient may die before it develops.

Dr. Harold N. Moyer, Chicago: I saw the fifth case described by Dr. Bassoe on one occasion but the opportunity for examining was none of the best. In this case there was a striking clinical resemblance to paretic dementia. The symptoms would become very pronounced, then subside, and his conduct in the periods of euphoria, which were marked, strongly suggested paresis. $\mathrm{He}$ was distinctly paretic on the left side and persistently leaned forward and to the left; he would straighten up, but would soon automatically resume this position. I expressed the opinion that he had a brain tumor but of its location I had no idea. I certainly never suspected that it was a subtentorial growth. Dr. Bassoe says the eyegrounds were normal. At the time I examined him it seemed to me that the left disk was somewhat altered but not significantly so.

Dr. Lawson G. Lowrey, Hatl.orne, Mass.: About a year and a half ago I made a necropsy on a case presenting a tumor presumably arising in the third ventricle and extending from there into the lateral ventricle. For two years the patient had been in Danvers Hospital with a diagnosis of paresis. The symptoms were largely those of paresis, the onset had been rather gradual, the individual was dull, extremely indifferent and had demented very rapidly, with a doubtful blood Wassermann and no satisfactory spinal fluid examination. This tumor, too, was a glioma. So far as any exact examination that had ever been made showed, there were no symptoms that might be referred to a tumor.

Dr. A. L. Skoog, Kansas City, Mo.: While these tumors of the third and fourth ventricles are difficult to diagnose, yet frequently you can suspect localization. Probably quite a number of errors have been made on account of not giving sufficient consideration to the chronology of the case. We know that in cases exhibiting these various symptoms, and particularly those referable to the cerebellum and the medullary centers, and also those due to the secondary internal hydrocephalus, there is an onset of the symptoms at different periods. I believe we should lay emphasis on carefully noting just when each symptom begins. In this respect a careful history is, of course, important. There are case histories that are accurate and others that are not.

Dr. Peter Bassoe, Chicago: I must repeat what I said at the outset: that the symptoms in these tumors are caused

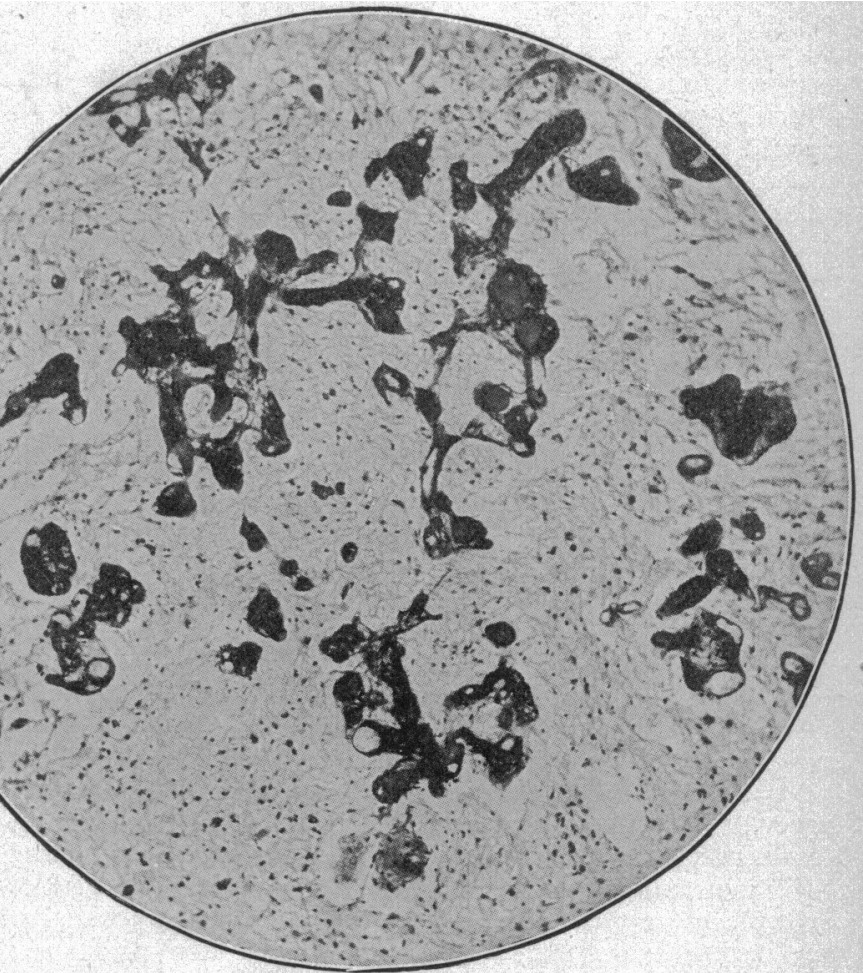

Fig. 13 (Case 5).-Photomicrograph of tumor showing hyaline transformation of vessels.

either by pressure or invasion of neighboring organs, or by hydrocephalus. Dr. Skoog says, by a study of a sequence of symptoms we may form some opinion as to where the tumor originated. In the case of the fourth ventricle, if a tumor starts from the choroid plexus, there would necessarily not be symptoms until a certain amount of hydrocephalus was produced. If the tumor starts from the floor you may get symptoms on the part of the cranial nerves, or if it starts from the vermes you may have early localized 
cerebellar symptoms. In the case of the third ventricle, quite necessarily the symptoms are those of hydrocephalus. We can hardly speak of any focal symptoms there unless the tumor has grown from the ependyma into the brain structure, or has started in some other structure and extended into the ventricle. In my only case of tumor of the third ventricle, the patient had a typical cerebellar ataxia. The very early loss of conjugate movements and early blindness, and the quite precocious development of hair and of the genital organs led us to suspect a tumor in the general vicinity of the pineal gland, or corpora quadrigemina, or in the third ventricle, but we did not venture to say in which of these structures the tumor might have started.

In regard to the diagnosis between tumors of the fourth ventricle and tumors starting in the cerebellum, this is extremely difficult. But if in a case with ordinary cerebellar tumor picture there is marked variation in the subjective feeling of the patient on changing position, together with quite a marked increase in cells and globulin of the spinal fluid, then I would be suspicious of a tumor in the fourth ventricle. In the case of which Dr. Moyer speaks, there was no change in the disks that I could make out, but I did not examine the patient during the last year of his life. I was told by three or four of the men who saw the case that they had never noted any change in the disks, but the patient was not under the observation of any one man during the whole period.

There is one aspect that has not been touched on here, and that is the possibility of any surgical treatment in these cases. In my three operated patients the surgical results were notoriously bad; one died on the table and the other two did not rally. Could we have done any better for those patients? It is only within a year that Professor Anton of Halle has written a paper seriously proposing operative procedure in cases of tumor of the fourth ventricle, providing it arises from the roof or choroid plexus. He says that at least half the tumors arise from the roof. By first doing a callosal puncture or puncture of the lateral ventricle, thus relieving the pressure from above, the suboccipital opening can be made with less shock. He believes it might be possible to go through the vermis, which usually has been gradually thinned out by the pressure, as was the case in some of my cases, or that we might go through the foramen Magendie, and remove the tumor. About ten years ago it was suggested by Henneberg that cysticercus cysts of the fourth ventricle might be removed in that way.

Sickness in Rural Heaith Districts.-During 3 the summer of 1915 the New York state department of health made an inquiry to determine the amount and nature of sickness usually and fairly constant in rural communities. Five townships and two villages in Albany County were the subject of this survey. The district was considered fairly typical of rural New York. The population of these townships numbered 5,676 , and the number included in the records 5,187 , or 91.2 per cent. of the total. The number of persons admitting that they were ill was 582 , or 11.2 per cent. of the population visited. An examination of 397 schoolchildren in a rural district of New York shows that 51.3 per cent. had defective teeth and 61.5 per cent. enlarged tonsils or adenoids. The total number of cases of illness in six townships and two villages was 1,242 , of which 688 were not under the care of a doctor. In this survey the investigators reported that teeth defects were generally present at all ages. This investigation brought out the further fact that while school inspection pointed out the defects of the children, no means was provided for the correction of such defects, and also that most people were willing to pay a moderate price for treatment but could not pay "fancy prices."

\section{THE PROGRESSIVE TORSION SPASM OF CHILDHOOD (DYSTONIA MUSCU- LORUM DEFORMANS)}

\section{A CONSIDERATION OF ITS NATURE AND SYMPTOMA- TOLOGY *}

J. RAMSAY HUNT, M.D.

Consulting Neurologist, New York Neurological Institute

\author{
NEW YORK
}

The subject which I would present for your consideration is that curious form of motor disturbance known as the progressive torsion spasm or dystonia musculorum deformans.

Dec. 17, 1910, Ziehen, ${ }^{1}$ at a meeting of the Berlin Psychiatric Society, demonstrated a child 10 years of age with a spasmodic affection of unusual type. Four similar cases had come under his observation, three in members of the same family. ${ }^{2}$ In all, the affection had been gradually progressive and was characterized by spasm and hypertonicity of the musculature, with curious twisting and torsion movements of the extremities and trunk. The muscular spasm was considerably increased by active movement and diminished during rest. The gait and station were chiefly affected and there was marked lordosis of the spine. The tendon reflexes were present but difficult to elicit, because of the tension and torsion of the muscles. Sensation and intelligence were not affected, and, in one of the cases, necropsy had revealed no essential lesion. All of the patients were Russian Jews.

In discussing the character of the motor disturbance, he stated that while there was a certain general resemblance to the movements of chorea and athetosis, these affections as well as hysteria could be definitely excluded. He regarded the affection as a special type of the degenerative spasmodic neuroses, allied to impulsive tics, and proposed the name "tonic torsion neurosis."

In 1911, Oppenheim ${ }^{3}$ followed with a more elaborate description of the disease, which he regarded as organic and not functional in nature, and emphasized the close relationship of the spasm to athetoid movements.

Oppenheim's cases, like those of Ziehen, began in childhood (from the eighth to the fourteenth year). All were either Russian or Polish Jews. The affection began insidiously in one of the extremities, either the leg or the arm; but eventually the muscles of the thigh, pelvis and spinal column were always chiefly affected. There was marked lordosis with clownlike, bizarre movements, and a curious disturbance of the gait which

\footnotetext{
* From the Neurological Wards of the Montefiore Home and Hospital.

* Read before the Section on Nervous and Mental Diseases at the Sixty-Seventh Annual Session of the American Medical Association, Detroit, June, 1916.

* Because of lack of space, this article is abbreviated in THE JOURNAL. The complete article appears in the Transactions of the Section and in the author's reprints.

1. Ziehen: Tonic Torsions Neurose, Neurol. Centralbl., 1911, xxx, ; Allg. Ztschr. f. Psychiat., 1911, lxviii, 281.

2. Schwalbe had "previously recorded this group of cases from Ziehen's Clinic as "Eine Eigenthumliche tonische Krampfform mit hysterischen Symptomen," Inaug. Diss., Berlin, 1908. lichen und jugend Ueber eine eigenartige Krampf Krankheit des Kindtonia Musculorum Deformans, Neurol. Centralbl., 1911, xxx, 1090.
} 